\title{
Authors' Reply to the Comment on: "Pulmonary Tuberculosis Seasonality Survey in the Fars Province, South of Iran”
}

\author{
Mohammad Javad Fallahi (iD ${ }^{1,{ }^{*}}$, Anahita Mirdamadi ${ }^{2}$ and Mohsen Moghadami ${ }^{3}$ \\ ${ }^{1}$ Pulmonary and Critical Care Division, Internal Medicine Department, Shiraz University of Medical Sciences, Shiraz, Iran \\ ${ }^{2}$ Nephrology Department, Internal Medicine Department, School of Medicine, Shiraz University of Medical Sciences, Shiraz, Iran \\ ${ }^{3}$ Internal Medicine Department, Shiraz University of Medical Sciences, Shiraz, Iran \\ "Corresponding author: Pulmonary and Critical Care Division, Internal Medicine Department, Shiraz University of Medical Sciences, Shiraz, Iran. Email: fallahimj@sums.ac.ir \\ Received 2020 February 03; Accepted 2020 February 07.
}

Keywords: Tuberculosis, Vitamin D, Warm Season

\section{Dear Editor,}

We thank the authors for their interest and comments on our manuscript (1). As it was mentioned by the authors, apparently more frequent diagnosis of tuberculosis in warm seasons may be a reflection of more frequent acquisition of organism during cold seasons, which is due to crowding, low immunity and low level of vitamin $\mathrm{D}$, and less diagnostic confusion with common upper respiratory tract infection $(2,3)$. However, due to the design of our study, which was retrospective and also poor recording of patient initiation symptom in our registry, we could not find the exact causes of seemingly tuberculosis diagnosis in warm seasons.

\section{Footnotes}

Conflict of Interests: The author declared no conflict of interests.

Funding/Support: None declared.

\section{References}

1. Sahraei Z, Niknami E, Saffaei A. Comment on: "Pulmonary tuberculosis seasonality survey in Fars Province, South of Iran". Shiraz E-Med J. e97381. doi: 10.5812/semj.97381.

2. Willis MD, Winston CA, Heilig CM, Cain KP, Walter ND, Mac Kenzie WR. Seasonality of tuberculosis in the United States, 1993-2008. Clin Infect Dis. 2012;54(11):1553-60. doi: 10.1093/cid/cis235. [PubMed: 22474225]. [PubMed Central: PMC4867465].

3. Koh GC, Hawthorne G, Turner AM, Kunst H, Dedicoat M. Tuberculosis incidence correlates with sunshine: an ecological 28-year time series study. PLoS One. 2013;8(3). e57752. doi: 10.1371/journal.pone.0057752. [PubMed: 23483924]. [PubMed Central: PMC3590299]. 